\title{
Walkability as a Culture Practice
}

\author{
Dimitra Riza ${ }^{1,2}$ \\ ${ }^{1}$ Democritus University of Thrace (DUTH), Greece \\ ${ }^{2}$ IKY Fellowship Siemens, Greece
}

Copyright $\bigcirc 2017$ by authors, all rights reserved. Authors agree that this article remains permanently open access under the terms of the Creative Commons Attribution License 4.0 International License

\begin{abstract}
The research approaches walking as an artistic performance and urban experience that provokes and reestablishes every day habits. Rethinking the urban space in terms of its anthropological and perceptual attributes and not only of its geometrical or morphological characteristics is the main focus of the paper. The hypothesis is that walking as a kinesthetic urban performance can affect the way of perceiving and experiencing the contemporary urban environment.
\end{abstract}

Keywords Walking, Embodied, Anthropological Space, Kinesthetic Experience

\section{Introduction and Methodological Approach}

The paper presents the importance of walking as a somatic everyday practice and the integration of the body into the urban environment while moving and exploring it; it evokes social participation and shared experience, provokes encounters and gaze crossings, explores the porosity of the city and transforms the existing spatial organizations and urban structures. The reactivation of the senses offers an embodied kinesthetic experience while city and body supplement and define each other [1].

As a methodology to approach the above-mentioned theory, art-historical examples in combination with urbanism-applied strategies are analyzed in terms of the relationship between the subject and the environment showing the evolution from the distanced subject that observes passively the world to the active participant who is contemplated into it. Later art examples of walking-performances are also presented as applied theoretical approaches that contribute to the discussion. The experiments of the contemporary art groups explore ways that walking can contribute to the urban culture and influence the daily life [2].

In this way, walking, as a strategy, becomes something much more than a mere everyday practice, as it can virtually create cultural paths and narratives that can participate and trans-form urban experiences.

\section{The Importance of the Somatic Experience}

\subsection{Art History and Urbanism Theoretical Background \\ Observer-Actor}

In the history of art, the relationship between the observer and the observed art piece reveals the way in which the environment is occasionally lived and experienced. The first separation between observer-subject and observed-object took place in the Greek tragedy, where the space of orchestra was set apart from the amphitheater. The Greek theater, as the word reveals- seeing from afar- manifested the "distanced view" that became the necessary condition for the development of the Renaissance perspective as well as for the establishment of the role of the observer [3].

In the Renaissance, the artists depicted the urban environment in an accurate and realistic way where the vanishing point, the geometric center of projection, and the position of the observer coincided. Perspective relied on a visual construct in which depth was articulated within a framed geometric field that was presented frontally to the observer, while a measured reality of the world was revealed [3].

The application of implied perspectival order (Jay, 1993) as scenographic arrangement of the modern city was very popular in the urbanism of the 17th and 18th century. Axial routes as a major structuring device directed the spectator's view toward monuments or squares placed on their axis, as focal points (Boyer, 1996). The representation of infinity was actually implemented in urbanism and garden design, such as the design of Versailles whose landscape layout implied the visual and actual connection with the city of Paris [3].

The significant break with Cartesian perspectivalism occurred with the entry of the body [4]. Art forms such as Dutch Painting or Impressionism placed the viewer inside the scene as an ambulatory presence, introducing the participatory eye, opposed to the static eye and the unique vanishing point of the Renaissance [5]. For instance, Vermeer minimized the importance of the frame that was very popular in the Renaissance, while Hieronymus Bosch 
and Peter Bruegel invited a participatory eye to travel across multiple events and visual aspects $[1,3]$. Additionally, in the art of 17th century the subject is transformed into embodied viewer and active participant [3]. In this context, the de-theatricalization of the painting-beholder relationship brought the collapse of the distance between observing eye and external scene [5].

Similar to Art, in Urbanism the act of seeing merged with the act of being seen [3]. Derrida describes the new urban phenomenon and the city as "the place where the spectator, presents himself as spectacle and is no longer either seer (voyant) or voyer" [5]. Earlier, in the Enlightenment, Rousseau introduced the festival as a model of total participation, opposing to the theater where spectators and actors were spatially divided [5]. In the contemporary theatricalized city people are not simply observers of a spectacle, but are a part of it on the stage with the other participants [6, 7]. The everyday experience with the embodied perception prevailed and the environment becomes an intimate action field.

So, the body is set to the center of the perception. Not only as the viewing point on the central perspective, but also, as the locus of reference, memory, imagination and integration. The human senses are activated and alerted in order to inhabit the city contrary to the isolated visual experience of Cartesianism and as Merleau-Ponty noted: "The lived perspective is that which we actually perceive, and not a geometric or photographic one" $[1,5,8]$.

\section{Moving as a Somatic Kinesthetic Experience}

In Art, Michelangelo conceives the human body only in action, and therefore he resisted making architecture through static geometric projections. Respectively, for Marcel Duchamp, the movement of the observer is indispensable for the meaning of the image to appear, and the painting calls for a new form of participation of the spectator, for a dynamic involvement in the process of creation. As a result to this theory, the observer has to walk around his ready mades in order to interpret them [3].

In urban terms the physical movement in the city offers various experiences and images that are timely evolved and unfolded in cinematic terms [9]. In contrast to the static optical center of Alberti, the moving eye and the body in action are set to the center of the moving experience and transform it into a kinesthetic one, while all senses are participating.

The visual field of the moving person becomes wider and deeper; with the movement of the body, the depth of the former perspective image is dynamically revealed to the observer. The depth is not anymore conceived as the prosaic interval between nearby and distant objects, but it is the dimension in which things envelop each other, according to Merleau Ponty [3]. We perceive, in short, not from a fixed point but along what Gibson calls a 'path of observation', a continuous itinerary of movement [10].
Additionally, movement perception, as a time-bounded perception, as Bergson defended it, is considered to become the most important sensual experience [5]. The temporality of the embodied experience was therefore crucial as it appears always in action and therefore time becomes as important as space [3].

\subsection{Urban Walking}

\section{Walking as an Embodied Sensual Practice}

Walking, as the physical movement in the urban environment is characterized as an individual everyday practice and as an elementary form to inhabit the city. It is an art of expression and it is to the urban system what the speech act is to language [11]. Actually, the movement of the body provokes an embodied and active experience of perceiving the environment. The constant interaction between walking body and environment turns the urban perceptual image into one single existential experience, where body and space do not separate from each other [1].

Further to the extended visual impressions, all senses are alerted and contribute to the perception of the landscape, as a set of tastes, colors and scents absorbed by the body [12]. In this way, the kinesthetic urban experience binds the sights, savors, sounds, tastes and textures with the moving body [13].

So, the walker without eliminating the role of the observer restores the sensual and physical contact of the subject with its environment, and walking is understood as the process where the live being loses and reestablishes equilibrium with his surroundings.

\section{Urban Walking Historical Background}

Revisioning the cities' layouts and structures, continuous networks that imply walking activities are recognizable. Historically, one of the first designed urban leisure promenade is found in the area of Acropolis, formed as a peripheral route around the holy rock, giving access to temples and other facilities, passing by fountains and going through Dionysos Theater by giving the walker the opportunity to become shortly part of the spectacle. Additionally, Panathenean Street that crosses diagonally the ancient Agora refers to the ritual itinerary that connects Eleusina with Acropolis during the Panathenean celebration.

Walking Promenades express mostly spaces for public action. Before the end of 18th century, public space was usually designed as an honorific place celebrating the power of king, while after the political revolutions the city space became the model of bourgeois public sphere [6].

Just before the bourgeois activities in the public space, the aristocratic tradition of providing limited public access to gardens and to open royal parks or gardens periodically was an established custom by 1700 . The provision of public promenades in the gardens, created the need for public amusement zones in the urban environment. For instance, Tiergarten in Berlin was opened to public in 1649 for 
"pleasure strolling" [14]. In the same period, Louis XIV transforms the city walls of Paris into tree-lined pleasure promenades, called "boulevards", while later, in the 18th century these parkways were lined with activities such as cafes or other amusement structures [14].

The evolution of boulevards in the urban design shows the tendency of bringing people to the streets in order to enjoy the city by strolling, watching and interacting with other people and with the urban environment. Urban design focuses on pleasure activities and shared experiences and walking promenades transformed them into leisure entertainment urban space [6]. Napoleon the III with his famous architect Hausmann, conceived of the architectural promenade not only as a connection strip to bind his city of Paris into one cohesive unit, but also as a narrative experience, a memory walk through the historic monuments and grandiose architectural facades [6]. The introduction of this "thematic" route acted as forerunner of the future tourist routes and walks that aligns monuments and sightseeing into a unified urban image.

\section{From Geometrical to Anthropological Space}

\subsection{Transformation of the Existing}

The walker interprets the existing urban characteristics and transforms them through his physical motion. Simultaneously, as he inhabits the environment, he becomes automatically an inseparable element of it that defines and re-shapes it. The inhabitation of the environment presumes that we are part of it; and through this practice of habitation it becomes part of us too [10]. The walker traverses the space and is in here, and not out there, and the environment is interpreted as a field of interwoven lines [15].

Alison and Peter Smithson defined the city as the place where people and objects are in constant motion and change [6]. While the urban environment changes and is being transformed from a physical into an empirical one, walking can be also considered as an architectural form, where the moving bodies shape dynamically the urban space [2]. An interactive relationship between the walker-subject and the city-object is being therefore established.

\section{Social Integration}

Crossing the urban environment except from creating a new interactive space, it creates the condition for shared experiences, unexpected encounters and interplays between the walkers. In this case the environment becomes the place of meetings and of social intercourse.

Walking is characterized as a social activity, but at the same time it can be described as an isolated personal one, in the way that each walker unit has a personal character of tactile apprehension and kinesthetic appropriation. For instance, the gait is unique for each person the walking fingerprint and expresses the way the city is being understood and interpreted [2]. Walking paths similar to itineraries are indeed organized around the subject-centered or journey of each traveller. Hence, the swarming mass is an innumerable collection of singularities. Their intertwined paths give their shape to spaces and create a composition of interdependent walking rhetorics [11].

\section{Urban Itineraries}

Usually the footprints of a walk are defined as an itinerary. The itinerary is presented as the methodological tool to approach the walking theory and transform it into an urban practice. Each itinerary is conceived as an ongoing process, which is each time newly redefined. It usually results from the combination of all possible paths of the urban fabric, and aims at turning the final destination reachable. As the city offers a sum of possibilities, the number of urban routes cannot be defined [16].

Different urban itinerary-route categories can contribute to the revitalization of the city, such as the "everyday" route, the "thematic" route, the "tourist" route, the "navigational" route, or the "leisure-lingering" route. The main differentiation among these route-types is between the predicted route and the unpredicted one. On one hand, the process of "wayfinding" and on the other hand the walking process itself, based on the Ruskian distinction between numbering habit and unmediated sensory experience respectively, stands out predefined routes from open-ended ones- routes with no final destination [17, 18].

Daily itineraries, for instance, impose their repetitions and rhythms, are mapped out before being actually realized and their goal is that the destination shall be reached as soon as possible. Similarly, the navigational routes are actually connecting point $\mathrm{A}$ (starting point) with point $\mathrm{B}$ (destination point) by indicating the shortest possible route $[18,19]$. The extended use of mobile phones and GPS systems provide new possibilities and by giving directions while destinations are easily to be found.

Conversely, when walkers become performers and walking becomes a pleasure-leisure practice, then the route is actually "disappearing" and the experience is substituting it [11]. For instance the $19^{\text {th }}$ century Parisian arcades, a covered city network that introduced alternative routes and passages inspired the bourgeois who looked for new unexpected experiences and new ways to enjoy the city. This playful arcade strolling was most characteristically represented by the Flâneur, a literary type, an emblematic archetype of urban, modern experience [14, 20].

Additionally, in the 60s, the Situationist drifter was the new Flâneur [16]. Situationists' constructed situations (Dart, 2010) alerted people to attractions and encounters and offered a new way of surveying the urban space [19]. They had to be ephemeral without a future and composed a synthesis of sublime moments [16]. The "drift" was conceived as a playful constructive behavior and offered new ways of surveying urban space. Their psychogeographic 
maps document the results of their experiments, representing the surreal disorientation of their drifts [16]. Getting lost is not always about dislocation, but it is about getting a feeling, free of the urban environment while experiencing it [21]. The drifts were therefore described as radical re-readings of the cities offering unexpected encounters and experiences [16].

\subsection{Choreography of Steps}

\section{Walking as an Urban Performance}

Rebecca Solvit describes walking as an embodied art performance unfolding in the urban scene: "One leg, a pillar holding the body upright between the earth and sky. The other a pendulum, swinging from behind. Heel touches down. The whole weight of the body rolls forward onto the ball of the foot. The big toe pushes off, and the delicately balanced weight of the body shifts again. The legs reverse position. It starts with a step and then another step". [21].

The renaissance of "Flanerie" and "Situationism" is re-loaded today as a bottom-up urbanism strategy and aims at the revitalization of the cities in a more sensual and experiential way. Similar to the $60 \mathrm{~s}$, the urban perception needs to change and people shall respond to their environment more in historical, cultural and social way, instead of aesthetical and more or less distanced one. By stressing on everyday life makes it possible to understand and perceive more the human scale [22]. The residents deserve their right to enjoy the street and to explore in detail the everyday; to discover new, sometimes blooming landscapes that attract the interest of their own towns [22].

Contemporary art groups explore ways by practicing alternative ways of experiencing the urban environment. For instance, the Grenoble based group Ici-Même, in a workshop called "En marche", in Paris, 2009, investigated the porosity of the city, by following a straight line on the map. Each path was not corresponding to existing moving networks, but could pass through buildings, patios, etc. "Some cities offer multiple routes parallel to public streets", mentioned Corinne Pontier, member of the group [2].

Additionally, researchers challenged the shortest destination route, and suggested instead the most beautiful one. Yahoo Labs in Barcelona worked out how to measure beauty of specific locations in the cities and designed an algorithm that chooses a route according to beauty criteria.

Artists constantly are developing methods of bringing art and life into closer contact. Experiments dealing with the city as a site of mystery aim at revealing the true nature of urban space, that lies beneath the flux of everyday [23].

\section{Conclusions}

Walking can manipulate and transform the existing spatial organizations; the embodied perception of the city in combination with the social interaction transforms the urban environment into an anthropological place of experiences. As walking is not just what the body does, but it is what the body is, it is foundational to culture [24]. Artists who tried to explore walking as a performance challenge the stereotypes for urban living. Their performances reverse the existing urban pattern in order to provoke the citizens to re-experience their city.

While contemporary city is mostly conceived as a visual distanced object, where the subject is isolated and distanced from the action field, walking brings back the relationship between the city and the people by revitalizing and reusing all their senses in order to inhabit and explore it.

Urban revitalization as a methodology aims at redeveloping particular areas and at increasing the city attractiveness and enhancement. Urban Promenades along rivers and coasts or labyrinthian paths in the historical cities are some examples of walking channels that upgrade urban life. The installation of pedestrian urban zones as urban strategy introduces for the people a new way to look and experience the city and opens up new possibilities of perception. Furthermore, following the new trend for health and exercise, the design of open places for the comfort and enjoyment of the pedestrian is one of the most important aspects of New Urbanism. Taken to the highest level of urbanism, the finest places in the world are cities with entire networks of car-free streets, known as pedestrian cities.

The way we move largely determines the way we live. The improvement of our life's quality, introducing a sustainable urban development, by using pedestrian movement, as the few human activities that has kept its primary form, is the new revolutionary urbanism's motto.

\section{REFERENCES}

[1] J. Pallasmaa. The eyes of the skin. Architecture and the Senses”, John Wiley \& Sohns Ltd., Chichester, West Essex, England, 2005

[2] K.O. Rourke. Walking and Mapping. Artists as Cartographers, the MIT Press, Cambridge Massachusetts, 2013

[3] A. Perez-Comez, L. Pelletier. Architectural Representation and the Perspective Hinge, The MIT Press, Cambridge Massachusetts, 1997

[4] H. Foster. Vision and Visuality, The Art Foundation, Discussions in Contemporary Culture, Number 2, Bay Press, Seattle, 1988

[5] M. Jay Martin. Downcast Eyes. The Denigration of vision in the twentieth century French thought, University of California Press, Berkley and Los Angeles California, 1993

[6] C.M. Boyer. The City of collective memory. Its Historical Imagery and Architectural Environments, The MIT Press, Cambridge Massachusetts, 1996

[7] K. Lynch. The image of the City, the MIT Press, Cambridge Massachusetts, 1960

[8] M. Ponty. Phenomenology of Perception, trans. Colin Smith, Routledge and Kegan Paul, London, 1962 
[9] G. Deleuze. Cinema 2. The Time Image”, Continuum, London, 1989

[10] T. Ingold. Being Alive. Essays on movement, knowledge and description, Routledge, London, 2011

[11] M. de Certeau. The practice of everyday life, University of California Press, Berkley and Los Angeles California, 1984

[12] F. Gros. A Philosophy of Walking, Verso, London New York, 2015

[13] B. Stafford. Visual Analogy. Consciousness as the Art of Connecting, The MIT Press, Cambridge Massachusetts, 1999

[14] S. Kostof. The City assembled. The elements of urban form through history, Thames and Hudson Ltd, London, 1992

[15] T. Ingold Tim. Lines. A Brief History, Routledge, London, 2007

[16] S. Sadler. The situationist city, The MIT Press, Cambridge Massachusetts, 1998

[17] I. Borden. Driving. In Restless Cities, Verso, London, New York, 2010
[18] M. Augé. In the Metro, University of Minnesota Press, Minneapolis, 2002

[19] G. Dart. Daydreaming, in Restless Cities, Verso, London, New York, 2010

[20] G. Shaya. The Flâneur, the Badaud, and the Making of a Mass Public in France, circa 1860-1910, American Historical Review 109 (2004)

[21] R. Solvit. Wanderlust. A history of walking, Granta Publications, London, 2014

[22] K. Von Kay and S. Voggenreiter (ed). En Passant. Reisen durch urbane Räume: Perspektiven einer anderen Art der Stadtwahrnehmung, Jovis Verlag, Berlin, 2010

[23] M. Coverley. Psychogeography, Pocket Essentials, Great Britain: 2010

[24] T. Ingold T. \& J.L. Vergunst J.L. (Ed). Ways of walking. Ethnography and Practice on Foot, Routledge, London, New York, 2008 